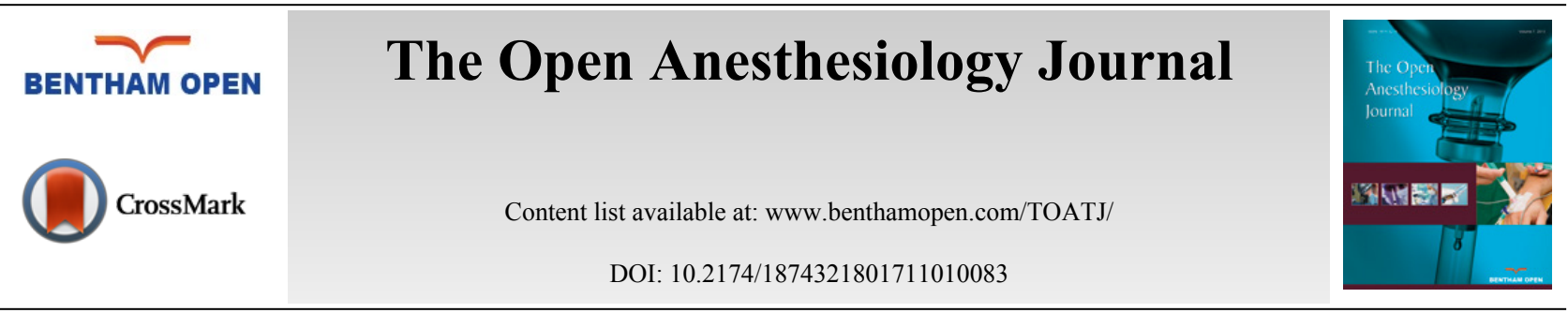

CASE REPORT

\title{
Adjustable Horseshoe Headrest as a Positioning Adjunct in Airway Management for a Giant Occipital Encephalocele
}

\author{
Habib Muhammad Reazaul Karim ${ }^{1, *}$, Muhammad Yunus ${ }^{2}$, Angkita Barman², Sonai Datta Kakati ${ }^{2}$ \\ and Samarjit Dey ${ }^{2}$ \\ ${ }^{I}$ Andaman and Nicobar Islands Institute of Medical Sciences \& GB Pant Hospital, Port Blair and NEIGRIHMS, \\ Shillong, India \\ ${ }^{2}$ North Eastern Indira Gandhi Regional Institute of Health and Medical Sciences (NEIGRIHMS), Shillong, India
}

Received: January 31, 2017

Revised: March 13, 2017

Accepted: June 08, 2017

\section{Abstract:}

\section{Background:}

Presence of a giant occipital encephalocele poses a challenge for laryngoscopy by hindering optimal positioning. Intubations in different positions, assistance and modification of table surfaces have been reported with different rates of success and complications in such cases.

\section{Method:}

We used an adjustable horseshoe headrest as a positioning adjunct in airway management in a few cases during 2015 - 2016 . Four babies were positioned with the help of the horseshoe headrest for direct laryngoscopy. These cases were then compared with previously conducted one more case whose trachea was intubated by the child's head beyond the edge after an unsuccessful attempt in lateral position.

\section{Result:}

All four cases positioned with adjustable horseshoe head rest were intubated successfully with mean $2 \pm 0.81$ attempts with $2.25 \pm$ 0.5 Cormack-Lehane laryngeal view. Significant complications were absent in the cases intubated by placing the head in horseshoe headrest as compared to the case performed in lateral position followed by placing the child's head beyond the edge of the table with assistants supporting the baby.

\section{Conclusion:}

This clinical paper discusses this infrequently reported modification, and also compares it with other positions and modifications commonly used in clinical practice.

Keywords: Airway, Laryngoscopy, Horseshoe headrest, Occipital encephalocele, Pediatric anesthesia, Cormack-lehane laryngeal views.

\section{INTRODUCTION}

Encephalocele is relatively common congenital neural tube defect with an incidence of 1 in 5000 births and $70 \%$ of the encephalocele are occipital [1]. Among the primary goals of the perioperative management of occipital encephalocele, gentle manipulation of the mass to prevent rupture and precise airway management are very important. Airway management when a giant encephalocele is present, can be challenging with difficulty in positioning and is

* Address correspondence to this author at the Andaman and Nicobar Islands Institute of Medical Sciences \& GB Pant Hospital, Port Blair and NEIGRIHMS, Shillong, India; Tel: +919531847117; E-mail: drhabibkarim@gmail.com 
commonly associated with difficult mask ventilation and intubation [1]. To overcome these problems anesthesiologists have used innovative ideas and techniques in clinical practices. In a series of cases, it was found that babies having giant occipital encephalocele were difficult to position and intubate the trachea in lateral position [2]. The positioning problem was more prominent in the cases having large occipital encephalocele [2]. They also found that successful tracheal intubation was possible by putting the head beyond the table in the cases which were unsuccessful in lateral position [2]. However they thought that this method was not helpful for patients with large occipital encephalocele because it needed two residents extra. We report airway management of a total of five cases of giant occipital encephalocele here. After a failed attempt of tracheal intubation in lateral position and the problems faced by placing the head beyond the edge of the table in the first case; we used adjustable horseshoe headrest as a positioning adjunct for airway management in subsequent four cases. This retrospective analysis of these cases was done to compare the number of direct laryngoscopy (DL) attempt required to intubate the trachea, laryngeal views along with the complications if any. These cases highlight the use of the horseshoe headrest in airway management and discuss the advantages and disadvantages of this modification with other commonly practiced positions and modifications.

\section{CASES}

\subsection{Case One}

A 14 days old female baby, born at term; weighing 3 kilogram was brought for surgical repair of a giant occipital encephalocele (13 x $11 \mathrm{~cm}$ approximate). The baby was kept in left lateral position and general anesthesia (GA) was induced with sevoflurane and $100 \%$ oxygen. Mask ventilation was found to be adequate and Fentanyl 5 microgram was injected through the in situ peripheral venous cannula. DL using Miller blade size 1 was attempted twice but was unsuccessful due to the inability to bring the external airway axis in to one alignment and view laryngeal inlet. Baby was then lifted and the head was placed beyond the edge of the table with one assistant supporting the head, neck and shoulder region; one supporting torso and pelvis and another assistant supporting the encephalocele. The anesthesiologist was unable to intubate the trachea even after $2^{\text {nd }}$ attempt with external manipulation and meanwhile the baby's oxygen saturation $\left(\mathrm{SpO}_{2}\right)$ fall below $80 \%$. Help was sought immediately and the baby was awakened and kept on oxygen until assistance and emergency airway management equipment arrived. The baby was re-anesthetized and finally the trachea was intubated on the fourth attempt using $2.5 \mathrm{~mm}$ internal diameter uncuffed endotracheal tube with a Cormack - Lehane grade 3 view. But the clinical course was complicated by bronchospasm, declining $\mathrm{SpO}_{2}$ and bradycardia which were immediately treated and the baby was stabilized successfully and the surgical procedure was completed uneventfully in prone position.

This failure and complications along with the involvement of multiple persons in relatively smaller working area forced the anesthesiologist team to rethink and the idea of using adjustable horseshoe head rest to support the head during airway management was considered.

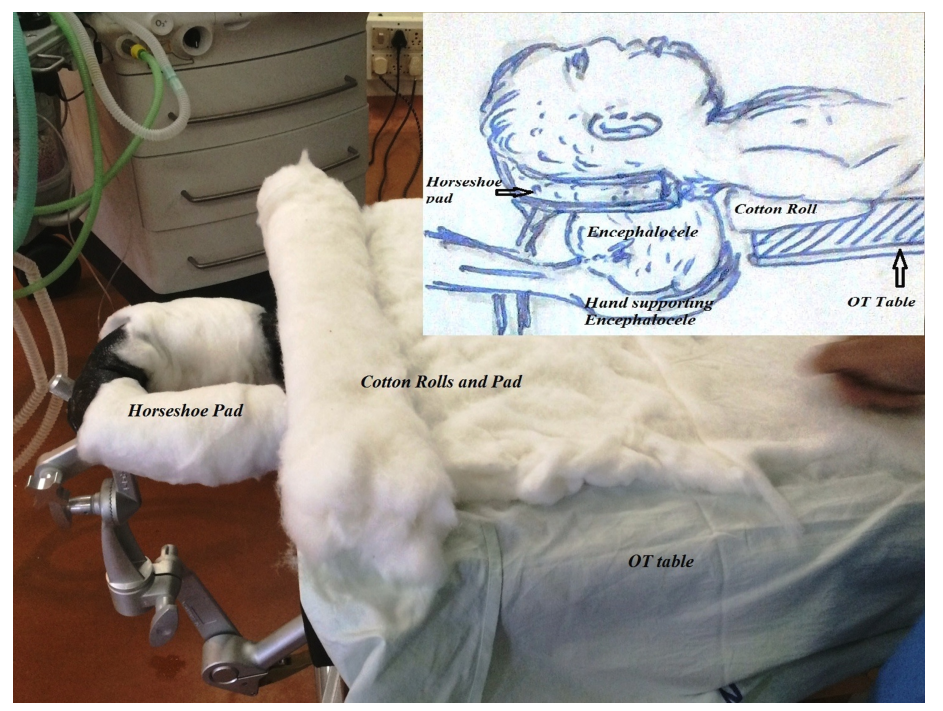

Fig. (1). Showing prepared table with a satellite drawing illustrating the concept of horseshoe headrest as a positioning adjunct for airway management. 


\subsection{Case Two to Five}

4 (four) male babies, with mean age and weight 66.5 days and 4.5 kilograms respectively; who were also posted for surgical repair of giant occipital enecepahalocele were intubated by placing the head over the horseshoe head rest. The horseshoe head rest was fitted with the operation table before bringing the baby to the operation table and covered with cotton padding. Cotton padding of the bed was also done along with roll under the shoulder area. Fig. (1) is showing one prepared table with a satellite drawing illustrating the concept in a simplified way.

Table 1. Age, sex and weight of the entire cases and their head position (SD - standard deviation).

\begin{tabular}{|c|c|c|c|c|c|c|}
\hline \multirow{2}{*}{$\begin{array}{l}\text { Case } \\
\text { No. }\end{array}$} & \multirow{2}{*}{$\begin{array}{c}\text { Head Position Used for Direct } \\
\text { Laryngoscopy }\end{array}$} & \multicolumn{2}{|c|}{ Age (days) } & \multirow{2}{*}{ Sex } & \multicolumn{2}{|c|}{ Weight (kilogram) } \\
\hline & & Value & Mean \pm SD & & Value & Mean \pm SD \\
\hline 1 & $\begin{array}{l}\text { Left lateral changed to head } \\
\text { beyond the edge of the table }\end{array}$ & 14 & & Female & 3 & \\
\hline 2 & \multirow{4}{*}{$\begin{array}{l}\text { Head positioned in horseshoe } \\
\text { headrest }\end{array}$} & 9 & \multirow{4}{*}{$66.5 \pm 59.16$} & Male & 3 & \multirow{4}{*}{$4.5 \pm 1.29$} \\
\hline 3 & & 115 & & Male & 5 & \\
\hline 4 & & 120 & & Male & 6 & \\
\hline 5 & & 22 & & Male & 4 & \\
\hline
\end{tabular}

Table 2. Direct laryngoscopy related data analyzed by unpaired t test using INSTAT software. (N- total number, SD standard deviation, CI- confidence interval, C\&L-Cormack-Lehane).

\begin{tabular}{|c|c|c|c|c|c|c|}
\hline \multirow{2}{*}{ Parameters } & \multicolumn{4}{|c|}{ On Horseshoe Headrest (N=4) } & \multicolumn{2}{c|}{$\begin{array}{c}\text { Lateral Followed by the Head Beyond } \\
\text { Operating Table (N=1) }\end{array}$} \\
\cline { 2 - 7 } & Range & Mean \pm SD & Median & $\mathbf{9 5 \%}$ CI & Mean \pm SD & Median \\
\hline No. of attempt & $1-3$ & $2.0 \pm 0.81$ & 2 & $0.70-3.29$ & $4 \pm 0.00$ & 4 \\
\hline C \& L view & $2-3$ & $2.25 \pm 0.50$ & 2 & $1.45-3.04$ & $3 \pm 0.00$ & 3 \\
\hline
\end{tabular}

Breathing circuit was filled with $8 \%$ sevoflurane with $100 \%$ oxygen. The difficult airway cart was kept readied and immediately available. Once the baby was brought to the operating table, the patient's head was adjusted so that the encephalocele was free of pressure in the adjustable horseshoe headrest. One assistant from the lateral side supported the mass by his one hand and another hand was kept free for external laryngeal manipulation if required. The prefilled circuit attached with mask was held and simultaneously $\mathrm{SpO}_{2}$ and other monitoring were put. The head rest was adjusted to make the external auditory meatus and sternum at the same horizontal level. Further drugs were given once mask ventilation was possible however no muscle relaxants were used. All cases were induced in similar ways and intubated while preserving the spontaneous ventilation. All the four babies positioned with the help of horseshoe were intubated successfully using Miller blade 1 and appropriate sized uncuffed endotracheal tubes. The maximum attempt required to intubate was 3 (three) in one of the case. The demographic parameters of all the babies are presented in Table 1. The mean number of attempts and Cormack-Lehane views are shown in the Table 2.

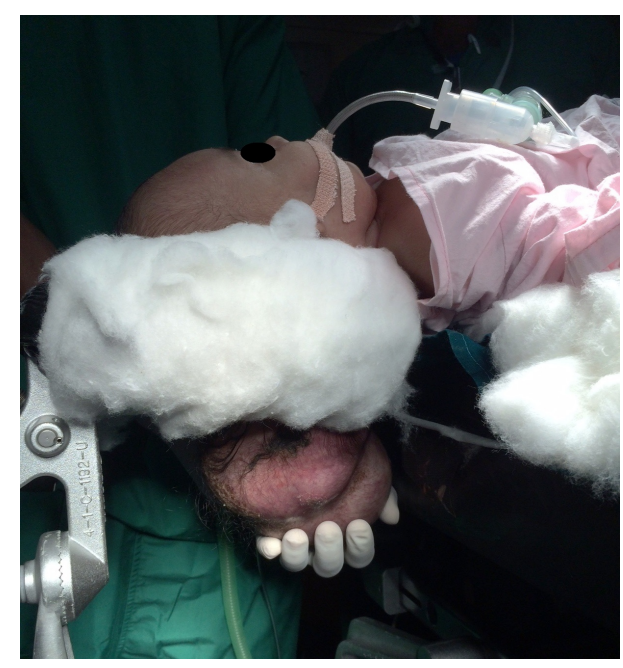

Fig. (2). Showing one baby intubated on the adjustable horseshoe headrest. 
No significant immediate complications were noted although fall of oxygen saturation up to $92 \%$ happened once in of these four cases which were immediately corrected by mask ventilation with oxygen. Fig. (2) is showing one of the babies on the horseshoe headrest just after successful intubation and confirmation of tube position.

\section{DISCUSSION}

It is a well known clinical fact that DL is a dynamic procedure and position adjustment is invariably required during DL [3]. Neck flexion and head extension is an important component of position adjustment to bring the oral, pharyngeal and laryngeal axis in to alignment for successful tracheal intubation. Giant occipital encephalocele hampers the head extension as well as neutral supine positioning of the head in a suitable way for DL. To overcome these problems anesthesiologists have attempted DL by keeping the child in lateral position, or placing the child's head beyond the edge of the table with manual supports from assistants $[1,4,5]$. The modifications like supporting the swelling with a doughnut, gel or cotton bolsters, folded surgical drapes etc. were also described [6 - 8]. One centre has reported successful intubation in $47.5 \%$ of cases in lateral position [1]. However reports of failure to intubate in lateral position followed by successful intubation by placing the child's head beyond the edge of the table with head supported by assistants has also been reported frequently [9 - 11]. We have also encountered the similar problem and although were able to intubate the trachea of the first baby on the fourth attempt by changing position to head beyond the edge of the table with multiple assistants supporting the head, neck, mass and torso; it was associated with complications nearly costing a life.

The horseshoe head rest is commonly used in neurosurgical operation theatre for positioning patients. It has soft / gel pads and is able to be moved in all 3 dimensions. The pads can be moved apart horizontally and the encephalocele can easily pass through the gap followed by readjustment to support the head. It can also be moved cephalo-caudally as well as vertically which can help in proper positioning of the head and neck during dynamic DL. The use of horseshoe head rest as an adjunct for airway management has been infrequently reported in published literature. One case of successful intubation was reported from Philadelphia and the authors have opined that positioning patient with an occipital encephalocele in the horseshoe headrest provides the anesthesiologist airway alignment and stability, creates optimal conditions for induction and tracheal intubation without increasing pressure on the encephalocele [12]. The same opinion is supported by the present findings. All the babies positioned with the help of adjustable horseshoe were successfully intubated with a mean attempt of 2 as compared to 4 attempts required to intubate in head beyond the edge of the table position. The difference however was not possible to be compared statistically as the sample in beyond the edge of the table was only one. The probable advantages and disadvantages of the lateral and manual suspension of the head beyond the edge of the table as compared to horseshoe headrest supported suspension are presented in (Table 3).

Table 3. Possible (not limited to) advantages and disadvantages of commonly used positions and its comparisons with horseshoe supported modification. (C \& L - Cormack-Lehane, DL- direct laryngoscopy).

\begin{tabular}{|c|c|c|c|}
\hline Position & Lateral Position & Head Beyond Edge with Manual Supports & Horseshoe Supported Supine \\
\hline Advantages & $\begin{array}{l}\text { Baby is supported solely by table } \\
\text { minimal hands around }\end{array}$ & $\begin{array}{c}\text { Dynamic DL relatively better } \\
\text { Conventional supine position maintained }\end{array}$ & $\begin{array}{c}\text { Head relatively stable during DL } \\
\text { Dynamic DL possible } \\
\text { Relatively better alignment of airway } \\
\text { Less congested area as less assistant hands } \\
\text { around } \\
\text { Relatively lower chance of pressure on mass } \\
\text { Conventional Supine position laryngoscopy }\end{array}$ \\
\hline Disadvantages & $\begin{array}{l}\text { Intubation is not easy and } \\
\text { conventional } \\
\text { Needs relatively more expertise } \\
\text { C \& L view is of higher grade } \\
\text { Failures are relatively high }\end{array}$ & \begin{tabular}{|} 
Multiple hands around and in action \\
Pressure on mass and raised pressure Possibility of \\
rupture is relatively higher \\
Head is not quite stable \\
Alignment dependant on multiple person
\end{tabular} & $\begin{array}{l}\text { Does not completely take away manual } \\
\text { support } \\
\text { One person needs to be ready to adjust the } \\
\text { horseshoe position }\end{array}$ \\
\hline
\end{tabular}

The present report is based on our experience of only a few cases and it clinches positively towards the use of adjustable horseshoe head rest as a positioning adjunct for airway management in giant occipital encephalocele cases. However, it is unable to say exactly whether the use of adjustable horseshoe is better over other position or not but it definitely gives us a research question for further evaluation. 


\section{CONCLUSION}

Adjustable horseshoe head rest appears as a viable adjunct for positioning of patients with giant occipital encephalocele during airway management. However, a prospective comparative study will be required to strongly suggest it.

\section{CONFLICT OF INTEREST}

The authors declare no conflict of interest, financial or otherwise.

\section{ACKNOWLEDGEMENTS}

Declared none.

\section{REFERENCES}

[1] Mahajan C, Rath GP, Dash HH, Bithal PK. Perioperative management of children with encephalocele: An institutional experience. J Neurosurg Anesthesiol 2011; 23(4): 352-6 [http://dx.doi.org/10.1097/ANA.0b013e31821f93dc] [PMID: 21633311]

[2] Yıldurım ZB, Avci E, Torun F, et al. Airway management for occipital encephalocele in neonatal patients: A review of 17 cases. J Neurosci Rural Pract 2011; 2(2): 159-61.

[http://dx.doi.org/10.4103/0976-3147.83583] [PMID: 21897680]

[3] El-Orbany M, Woehlck H, Salem MR. Head and neck position for direct laryngoscopy. Anesth Analg 2011; 113(1): 103-9. [http://dx.doi.org/10.1213/ANE.0b013e31821c7e9c] [PMID: 21596871]

[4] Kumar R, Jain S, Mehta RK, Trivedi S. Anaesthetic management of giant encephalocele. Int J Res Med Sci 2015; 3: 3889-92. [http://dx.doi.org/10.18203/2320-6012.ijrms20151464]

[5] Singh H, Singh D, Sharma D, Tandon MS, Ganjoo P. Perioperative challenges in patients with giant occipital encephalocele with microcephaly and micrognathia. J Neurosci Rural Pract 2012; 3(1): 68-70. [http://dx.doi.org/10.4103/0976-3147.91949] [PMID: 22346198]

[6] Pahuja HD, Deshmukh SR, Lande SA, Palsodkar SR, Bhure AR. Anaesthetic management of neonate with giant occipital meningoencephalocele: Case report. Egypt J Anaesth 2015; 31: 331-4. [http://dx.doi.org/10.1016/j.egja.2015.03.004]

[7] Mowafi HA, Sheikh BY, Al-Ghamdi AA. Positioning for anesthetic induction of neonates with encephalocele. Inter J Anesthesiol 2000; 5: 3.

[8] Cevik B, Orskıran A, Yilmaz M, Ekti Y. Anesthetic management of a newborn with giant occipital meningoencephalocele: Case report. International Journal of Case Reports and Images 2012; 3(8): 10-2.

[9] Goel V, Dogra N, Khandelwal M, Chaudhri R. Management of neonatal giant occipital encephalocele: Anaesthetic challenge. Indian J Anaesth 2010; 54(5): 477-8. [http://dx.doi.org/10.4103/0019-5049.71022] [PMID: 21189892]

[10] Dey N, Gombar KK, Khanna AK, Khandelwal P. Airway management in neonates with occipital encephalocele: Adjustments and modifications. Paediatr Anaesth 2007; 17(11): 1119-20. [http://dx.doi.org/10.1111/j.1460-9592.2007.02311.x] [PMID: 17897287]

[11] Manhas Y, Chinnan NK, Singh AK. Neonatal airway management in occipital encephalocele. Anesth Analg $2006 ; 103(6): 1632$. [http://dx.doi.org/10.1213/01.ane.0000247194.66024.d0] [PMID: 17122307]

[12] Black SA, Galvez JA, Rehman MA, Schwartz AJ. Images in anesthesiology: Airway management in an infant with a giant occipital encephalocele. Anesthesiology 2014; 120(6): 1504.

[http://dx.doi.org/10.1097/ALN.0b013e31829f028a] [PMID: 23788049]

(C) 2017 Reazaul Karim et al.

This is an open access article distributed under the terms of the Creative Commons Attribution 4.0 International Public License (CC-BY 4.0), a copy of which is available at: (https://creativecommons.org/licenses/by/4.0/legalcode). This license permits unrestricted use, distribution, and reproduction in any medium, provided the original author and source are credited. 